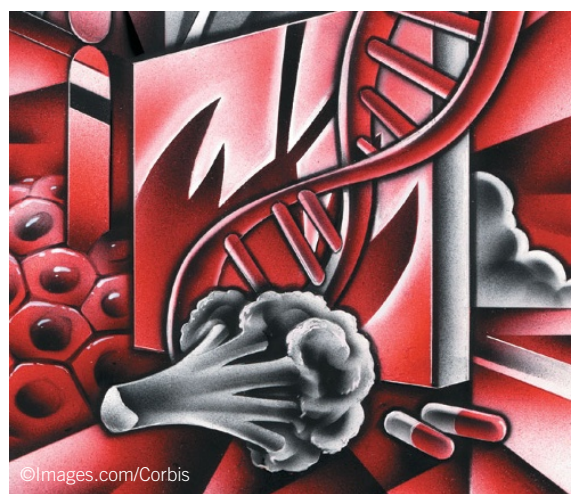

Industry observers hope that the US government's attention to the biotech sector will increase research funding.

ees, many investors say that small biotech companies could use a boost from the federal government. "Biotech is hugely capital intensive," says Christofferson. "Policymakers ought to seek ways to enhance the probability of success of these companies by providing economic or

tax incentives. Those would be really welcome," he says.

Policymakers may also note that more than $10 \%$ of firms conducting defense-related work expect, in the next three years, to rely on foreign employees with temporary visas or work permits. "We've heard anecdotally, for instance, that chemists are in short supply," says Laney-Cummings. "So the government will be looking at that."

The DoC expects to release the final results and analysis of its survey in September. "We've been pushing the government to collect data on biotech companies for about four years now," says Erickson. In addition to helping shape policies on healthcare or agriculture, he says, the survey more broadly highlights the importance of biotechnology, how fast the field is growing and how important it is to the economy. "So that gets policymakers to pay attention. As a result, I think we're going to see more money put into biotech across the board."

Alexandra Goho, Washington

\title{
EU directive on clinical trials penalizes small sponsors
}

Smaller EU biotech companies and public funders of clinical research are concerned that an EU directive passed in 2001 and designed to harmonize provisions governing clinical research across Europe doesn't take their needs into account because it was modeled on certain clinical trial practices of the pharmaceutical industry.

The directive (2001/20), which must be transposed into national law by May 2004, standardizes procedures for gaining approval to begin and manage a clinical trial. It also lays down Good Manufacturing Practice standards for the manufacture of drugs and provides for their quality assurance. The directive also provides Good Clinical Practice standards for safety monitoring of patients in trials, sets out procedures for reporting and recording adverse drug reactions, and gives rules for the import and labeling of drugs.

The main point of contention is that the directive allocates all responsibilities for initiating, funding and managing the risk and quality of trials to a single 'sponsor' organization that will carry the full legal liability for the trials and will therefore need to buy insurance. The directive is not set up to accommodate publicly funded trials, which are often organized by several partners, including charities and hospital trusts. These partners are unlikely to be willing to assume overall legal responsibility because they divvy up the different sponsor requirements. "At the moment, there is real concern that the legal requirements for a sponsor will not be able to be met by the major public funders," says Stephen Evans pharmacoepidemiologist and chair of the Medical Research Council (MRC; London, UK) committee that assessed the impact of the directive.

In addition, trials performed with the aim of gaining market authorization may be costly, but pharmaceutical companies recover their costs directly from sales. In contrast, publicly funded research trials are not always trying to bring a new drug to the market and are therefore unlikely to generate income to cover their costs. "You cannot regulate a trial undertaken to gain a marketing authorization the same way you would publicly funded multicenter studies," says Evans.

Whereas all the EU member states are currently transposing the directive into their national law, the UK is widely viewed as a leader of clinical research in Europe and therefore has more to lose than other EU member states.

Until now, the sole approval of an ethics committee was required to start healthy volunteer studies in the UK. "This system has been shown safe over many years and has also attracted companies from abroad," says Martin Edwards chair of the regulatory committee of the UK Bioindustry Association (London) and CEO of ReNeuron (Guildford). Beginning such studies under Directive 2001/20 requires approval by national regulatory agencies in each country at an early stage, thus increasing red tape and reducing the UK's attractiveness for clinical trials.

The six biggest medical research funders in the UK, including the MRC and Cancer Research UK (CRUK; London, UK) sent a letter last May expressing concerns to Alan Milburn, the UK secretary of state for health, who has since been replaced by John Reid. "The devil is in the details, so we are trying to influence the directive transposition," says Richard Sullivan, head of clinical programs for CRUK. The six funders hope the transposition of the directive into UK law will introduce flexibility for publicly funded research trials and avoid some of the problems of single sponsorship.

All member states need to similarly adapt the directive so that it agrees with their respective national laws; any significant differences between countries could form barriers to performing high-quality clinical trials. "Pan-European trials risk getting more complicated and expensive because all key topics from ethical approval to monitoring are open to broad interpretation by member states," points out Françoise Meunier, director general of the European Organization for Research and Treatment of Cancer (Brussels, Belgium), which enrolls over 6,000 patients each year. As a result, the law could increase costs and delays in the approval process across Europe.

Further delays could also affect small biotech firms at the approval stage for products, because the time for regulatory review will be 60 days for most small molecule applications, but review for cell and gene therapies could easily take six months. "I think the small companies perspective has been a little bit forgotten. Large pharmaceutical companies have been involved in the process [of writing the directive], but companies working on the biotech products of the future were not," says Erik Tambuyzer, chair of the healthcare board at EuropaBio (Brussels, Belgium) and vice president of corporate affairs for Genzyme in Europe (Brussels, Belgium). Edwards agrees: "Companies working in those fields will think twice before trying to start an initial study in Europe."

Anna Meldolesi, Rome 